\title{
Evolving role of platelet function testing in coronary artery interventions
}

\author{
This article was published in the following Dove Press journal: \\ Vascular Health and Risk Management \\ 7 February 2012 \\ Number of times this article has been viewed
}

\section{Rakesh K Sharma' \\ Donald J Voelker' \\ Rohit Sharma' \\ Hanumanth K Reddy' \\ Harvinder Dod' \\ James D Marsh ${ }^{2}$}

'Medical Center of South Arkansas, ${ }^{2}$ Division of Cardiology, University of Arkansas for Medical Sciences, Little Rock, AR, USA

Correspondence: Rakesh K Sharma Heart and Vascular Institute of South Arkansas, 700 West Grove Street, El Dorado, AR-71730, USA

$\mathrm{Tel}+$ I 8708755540

Fax + I 8708755548

Email rsharma@uams.edu
Abstract: The substantial reduction in ischemic events provided by the dual antiplatelet regimen with aspirin and clopidogrel is well documented in patients with acute coronary syndrome and patients undergoing percutaneous coronary intervention. Recently the variable response to the antiplatelet agents has received considerable attention after several "boxed warnings" on clopidogrel. This led to intense controversy on pharmacokinetic, pharmacodynamic, and pharmacogenomic issues of antiplatelet drugs, especially clopidogrel. Research use of platelet function testing has been successfully validated in identifying new antiplatelet drugs like prasugrel and ticagrelor. These platelet function assays are no longer regarded just as a laboratory phenomenon but rather as tools that have been shown to predict mortality in several clinical trials. It is believed that suboptimal response to an antiplatelet regimen (pharmacodynamic effect) may be associated with cardiovascular, cerebrovascular, and peripheral arterial events. There has been intense controversy about this variable response of antiplatelet drugs and the role of platelet function testing to guide antiplatelet therapy. While the importance of routine platelet function testing may be uncertain, it may be useful in high-risk patients such as those with diabetes mellitus, diffuse three vessels coronary artery disease, left main stenosis, diffuse atherosclerotic disease, and those with chronic renal failure undergoing percutaneous coronary intervention. It could also be useful in patients with suspected pharmacodynamic interaction with other drugs to assure the adequacy of platelet inhibition. While we wait for definitive trials, a predictive prognostic algorithm is necessary to individualize antiplatelet therapy with P2Y12 inhibitors based on platelet function assays and genetic testing.

Keywords: platelet function testing, platelet function assay, clopidogrel, coronary artery disease, acute coronary syndrome, coronary artery stenting

\section{Background}

The optimal use of dual antiplatelet treatment in acute coronary syndromes is evolving. While the guidelines from the American College of Cardiology and American Heart Association are largely based on population-based studies, physicians are faced with the management of individual patients who do not fit the published guidelines. Dual antiplatelet treatment has been shown to reduce the major adverse cardiovascular events after percutaneous coronary interventions (PCI), which is believed to be due to the efficacy of antiplatelet drugs. ${ }^{1,2}$ However, the response variability of patients to antiplatelet drugs, especially clopidogrel, can lead to pharmacodynamic failure, which may translate into clinical failure. The use of clopidogrel, a thienopyridine, in combination with aspirin is based on American College of Cardiology/American Heart Association guidelines on the basis of multiple trials. ${ }^{1,2}$ 
Dual antiplatelet therapy is recommended for 1 month after bare-metal stents and 12 months after drug-eluting stents. ${ }^{3}$ Premature cessation of dual antiplatelet therapy is associated with increased risk for cardiovascular events and stent thrombosis, ${ }^{4}$ a devastating complication.

The variable response to antiplatelet agents is wellknown and has garnered more attention after several "boxed warnings" on clopidogrel. Three sequential boxed warnings on clopidogrel have led to intense controversy. There is a concern about the suboptimal response to clopidogrel, which may be due to genetic polymorphism affecting the metabolic pathways and generation of the active metabolite leading to decreased pharmacodynamic effect. However, it is not clear if the pharmacodynamic failure by platelet function assay (PFA) translates into decreased clinical efficacy. It is believed that the suboptimal response to antiplatelet regimen (pharmacodynamic effect) may be associated with cardiovascular, cerebrovascular, and peripheral arterial events. 5,6 There has been intense controversy in regard to this variable response of antiplatelet drugs and the role of platelet function testing to guide antiplatelet therapy. This review will focus on the pharmacokinetic and pharmacodynamic aspects of antiplatelet drugs (thienopyridines and nonthienopyridines) and role of platelet function testing in guiding therapy.

\section{Pharmacokinetics of antiplatelet drugs; P2Y I 2 receptor antagonist}

Thienopyridine drugs, such as ticlopidine, clopidogrel, and prasugrel, and the nonthienopyridine ticagrelor bind to the P2Y12 adenosine diphosphate (ADP) receptor to initiate the clinical response. Ticlopidine, clopidogrel, and prasugrel are prodrugs that require biotransformation to active metabolites for their final effect on platelet aggregation, whereas ticagrelor does not require metabolic activation to elicit its antiplatelet effect. Ticagrelor and its active metabolites are approximately equally potent. It is well-known that clopidogrel has a substantial variability in pharmacodynamic response among $15 \%-40 \%$ patients..$^{7-12}$

Thienopyridines are rapidly absorbed and metabolized in the intestine and liver to generate active metabolites for the inhibition of platelet activation. These active metabolites bind to the P2Y12 receptor on the platelet leading to irreversible platelet inhibition. Ticagrelor, a nonthienopyridine, and its metabolite cause reversible platelet inhibition with equal potency. The half-life of ticagrelor is approximately 7 hours ( 9 hours for the active metabolite). All thienopyridines require the CYP450 system to convert the prodrugs to active metabolites, but the pathways leading to active metabolites are different. Ticagrelor, a nonthienopyridine, is mainly metabolized by CYP3A4 of the CYP450 system.

The pharmacokinetics of ticlopidine has not been well investigated. Maximum plasma concentration is reached in 1-3 hours after a single oral dose of $250 \mathrm{mg}$ and steady state after 3-5 days. ${ }^{13}$ Ticlopidine is metabolized by at least five main pathways, ${ }^{14}$ leading to a minimum of 13 different metabolites, the majority of which are inactive with only one of the metabolites expressing its antiplatelet effect. ${ }^{13}$ A maximal level of clopidogrel active metabolite is reached in 1 hour ${ }^{15,16}$ and the plasma concentration of clopidogrel active metabolite is dose dependent up to $600 \mathrm{mg} .{ }^{16-18}$ Maximum concentration of the active metabolite of prasugrel is reached 30 minutes after dosing. ${ }^{10,17,19}$ Clopidogrel is metabolized by two different pathways. One pathway leads to $85 \%$ clopidogrel to inactive metabolite, while the remainder goes through a second pathway by two oxidation steps via CYP450 enzymes. CYP2C19 is involved in both of these steps. ${ }^{20,21}$ Since CYP2C19 is the predominant enzyme, the genetic variation in this enzyme leads to variable production of active metabolites, leading to variable response. ${ }^{22,23}$ In contrast, prasugrel undergoes a rapid de-esterification to an intermediate thioactone, which is then converted into active metabolite by a single CYP-dependent step $^{24-26}$ and pharmacokinetics and pharmacodynamics are not affected by genetic variation of CYP polymorphism..$^{20,23}$ Ticagrelor and cangrelor are reversible inhibitors of P2Y12 ADP receptor and do not require metabolic activation. Ticagrelor is rapidly absorbed and undergoes enzymatic degradation to its active metabolite ${ }^{27,28}$ with maximum active metabolite and pharmacodynamic effects in 1-3 hours and plasma half-life of 7-9 hours. Cangrelor reach steady state within 30 minutes of the start of intravenous infusion. It has very short plasma half-life of 9 minutes. ${ }^{29}$ Elinogre $^{30}$ is a direct reversible $\mathrm{P} 2 \mathrm{Y} 12$ receptor blocker. It is the first antiplatelet agent that may be administered either intravenously or orally which may facilitate a smooth transition from acute to long-term therapy. This is not approved for use in USA at the time of writing.

\section{Pharmacodynamics of antiplatelet drugs; P2Y I 2 receptor antagonist}

Platelet activation occurs with the rupture of plaque in the culprit vessel or at the implantation of coronary stents. It involves several platelet activators, including thrombin, thromboxane A2, and ADP that work through two receptors on the platelets, namely P2Y1 and P2Y12. ${ }^{31}$ Although the binding of ADP to both of these receptors is necessary for platelet aggregation, P2Y12 is the predominant receptor 
responsible for activation and aggregation of platelets via activation of glycoprotein (GP) IIb/IIIa receptor. ${ }^{32,33}$ Binding of ADP to these $\mathrm{P} 2 \mathrm{Y} 12$ receptors stimulates activation of GP $\mathrm{IIb} /$ III a receptors leading to enhanced platelet degranulation, thromboxane production, and platelet aggregation. ${ }^{34}$ Therefore, during coronary intervention, P2Y12 inhibition and inhibition of thromboxane production with acetylsalicylic acid is needed, in addition to antithrombotic regimens. ${ }^{35}$ Despite this dual antiplatelet therapy with acetylsalicylic acid and clopidogrel, $15 \%-40 \%$ of patients show poor pharmacodynamic response as determined by ADP-induced platelet aggregation. ${ }^{9,27,28,36}$ Also, many trials have shown that such a low inhibition of platelets with poor pharmacodynamic response may lead to higher risk of stent thrombosis in such patients. ${ }^{5,37-39}$

At the present time, there are three approved thienopyridines and one nonthienopyridine for use after coronary artery stenting. Ticlopidine is not clinically used much due to its side effect profile. There is little published data on its pharmacodynamic effect and little is known about the interaction between the plasma concentration of its active metabolites and its pharmacodynamic effect. Maximum platelet inhibition occurs 3-4 days after daily dosing in healthy volunteers and recovery of platelets occurs 3-4 days after discontinuation. The combination of ticlopidine and aspirin has been shown to increase platelet inhibition..$^{40,41}$

The maximal pharmacodynamic effect of clopidogrel, with an average $30 \%$ inhibition of platelet aggregation, occurs at 4-5 hours after oral loading of $300 \mathrm{mg}$ of clopidogrel. . $^{-9,14,42}$ PFAs have shown poor pharmacodynamic effect in 15\%-40\% patients. $^{7-12}$ Doubling the loading dose from 300 to $600 \mathrm{mg}$ results in maximal inhibition of platelet aggregation at 2-3 hours with additional average increase of $10 \%-15 \%$ inhibition of platelet aggregation. ${ }^{12,18,43-45}$

Enhanced inhibition of platelet aggregation (IPA) with prasugrel was documented in a small substudy of Trial to Assess Improvement in Therapeutic Outcome by Optimizing Platelet Inhibition with Prasugrel (TRITON-TIMI [Thrombolysis In Acute Myocardial infarction] 38) ${ }^{46}$ Maximal inhibition of platelet aggregation inhibition with prasugrel was observed promptly within 15-30 minutes and 60\%-70\% inhibition of platelet aggregation within 2-4 hours. ${ }^{7,9,10,17,47}$ Peak inhibition of platelet aggregation after dosing with prasugrel was achieved with a mean of $84.1 \% \pm 9.2 \%$. Prasugrel loading with $60 \mathrm{mg}$ was associated with rapid onset of inhibition of platelet aggregation by 1 hour with approximately $90 \%$ of patients having more than $50 \%$ inhibition of platelet aggregation by 1 hour. $^{7}$ Patients who are poor responders to clopidogrel respond adequately to prasugrel ${ }^{7,48}$ and during the mainte- nance phase switching from clopidogrel to prasugrel with or without loading dose further improves the pharmacodynamics effect. ${ }^{36,48}$ The maximum IPA effect of ticagrelor was reached around 2 hours and was maintained for at least 8 hours after loading of $180 \mathrm{mg}$ and inhibition is sustained with maintenance dose of $90 \mathrm{mg}$ twice per day. The mean maximum IPA following the last dose of ticagrelor was $88 \%{ }^{27,28}$ Cangrelor is an intravenous direct-P2Y12 inhibitor and maximum pharmacodynamics effect is attained in 15 minutes with rapid reversal on discontinuation. ${ }^{29}$

\section{Evaluation of pharmacodynamic effect by platelet function assay (PFA)}

Recently, three sequential warnings, including a "boxed warning" for clopidogrel, ${ }^{49}$ have led to intense controversy regarding pharmacokinetic, pharmacodynamic and pharmacogenomic issues of antiplatelet drugs. These boxed warnings were concerned with the sub optimal antiplatelet effect of clopidogrel, due to its need for biotransformation by CYP450 to an active metabolite. Patients with the hypofunctioning CYP2C19 alleles have shown higher rates of cardiovascular events among those undergoing PCI in acute coronary syndromes. ${ }^{22}$ This warning further emphasized the need to identify such genetic polymorphism and encouraged the use of alternative antiplatelet agents. This warning followed an open label, yet to be published, study of 40 healthy volunteers, including ten individuals with varying degrees of CYP2C19 function, including poor metabolizer, intermediate metabolizer, and extensive and ultrarapid metabolizer groups.$^{50}$ These individuals were tested with either a $300 \mathrm{mg}$ loading dose and $75 \mathrm{mg}$ maintenance or a $600 \mathrm{mg}$ loading dose and $150 \mathrm{mg}$ maintenance dose of clopidogrel. End points were concentration of active metabolite (pharmacokinetic issue) and inhibition of platelet aggregation (pharmacodynamic issue) by PFA. The main finding was decreased exposure to active metabolites and increased platelet aggregation in the poor metabolizer group compared with other groups.

\section{PFAs}

The following statement underscores the discussion regarding PFA: "Do we manage hypertension without monitoring blood pressure? Do we manage diabetes mellitus without monitoring glucose? Do we manage warfarin without monitoring INR [international normalized ratio]? So why do we use antiplatelet regimen without monitoring platelet function testing?" 52 Unfortunately, approximately $30 \%$ of patients with acute coronary syndrome undergoing PCI and treated with clopidogrel had $<30 \%$ inhibition of platelet aggregation. ${ }^{51}$ 
Sharma et al emphasized the need of PFA to recognize such hypo- or nonresponders. ${ }^{52}$ Moreover, there are several studies (see Table 2) supporting the role of PFA based on outcome studies. There are many different types of PFAs, which have methodologies ranging from simple to complex. Different methods evaluating platelet function revolve around measurement of platelet aggregation, platelet reactivity, platelet receptor expression, measurement of platelet-released factors on activation, and intracellular platelet signaling. Often the question is about the extent of the ideal inhibition of platelet aggregation needed for effective clinical efficacy. While there is no standard definition of hyporesponsiveness, nonresponsiveness, or resistance to antiplatelet drugs based on platelet function testing, it is important to identify these hypo- or nonresponders to clopidogrel by PFA.

Hyporesponsiveness to clopidogrel can be secondary to several factors, including age, body mass index, diabetes, dyslipidemia, chronic renal disease, genetic polymorphism, and pharmacodynamic interaction with concomitant use of other drugs. In patients on a long-term dual antiplatelet regimen, guidelines have recommended the use of proton pump inhibitors (PPIs) ${ }^{53}$ to prevent gastrointestinal bleeding. However, there is an ongoing debate about the increase in major adverse cardiovascular events when PPIs are used in conjunction with clopidogrel, leading to the US Food and Drug Administration (FDA) warning that one PPI (omeprazole) reduces the antiplatelet activity of clopidogrel by $50 \%$. Such strong pharmacodynamic interaction between clopidogrel and a PPI underscores the need for an objective testing to exclude the attenuation of antiplatelet effect through the use of concomitant drugs such as omeprazole.

The role of the concurrent PPI use with clopidogrel and their effect on platelet function were assessed in analysis of Prasugrel In Comparison to Clopidogrel for Inhibition of Platelet Activation and Aggregation and TRITONTIMI 38..$^{36,54}$ These trials showed that PPIs lowered the inhibition of platelet aggregation significantly in patients taking a PPI and clopidogrel simultaneously. The association between PPI use, inhibition of platelet aggregation, and clinical outcome was assessed by analysis of the Prasugrel In Comparison to Clopidogrel for Inhibition of Platelet activation and Aggregation and TRITON-TIMI 38 trials by O'Donoghue et al. ${ }^{55}$ In this study, no association was found between the use of PPI and clinical outcome for patients treated with clopidogrel and prasugrel. However, FDA warnings began a debate in the medical community that has often centered on the decreased efficacy of clopidogrel with concomitant use of PPIs. ${ }^{56}$
Variable platelet inhibition occurs as a result of genetic polymorphism, leading to different levels of active metabolite availability, which in turn leads to variable platelet inhibition that can be recognized by PFA. The underlying genetic variability is due to variation in alleles (nucleotides). One important and well-recognized genetic polymorphism is the CYP2C19 polymorphism. Mega et al investigated the association of CYP2C19 and plasma concentration of clopidogrel metabolite and its pharmacodynamic effect on platelet function in healthy volunteers. ${ }^{22}$ This association of this genetic role of CYP2C19 polymorphism translated into cardiovascular outcomes in a subgroup of 1477 patients in the trial "to assess improvement in therapeutic outcome by optimizing platelet inhibition with Prasugrel-TIMI 38."22 Carriers with one hypofunctioning allele of CYP2C19 had a decreased level of clopidogrel metabolite with reduction in antiplatelet activity by platelet function testing. Consequently, there was an increased risk of cardiovascular death, acute myocardial infarction or stroke in carriers of the hypofunctioning allele of CYP2C19. Furthermore, those with the CYP2C19*2 allele had a three-fold increase of stent thrombosis. While genetic studies are important in evaluating CYP2C19 polymorphism, ${ }^{57}$ polymorphism of gene $A B C B 1$, polymorphism of CYP3A4, CYP3A5, CYP2B6, or genetic polymorphism of $\mathrm{P} 2 \mathrm{Y} 12$ receptors,${ }^{58}$ the end result is a variable inhibition of platelet aggregation in response to clopidogrel. Such attenuation of the antiplatelet effect of clopidogrel can be measured by PFA. While the importance of routine platelet function testing may be uncertain, it may be useful in high-risk patients such as those with diabetes mellitus, diffuse three vessels coronary artery disease, left main stenosis, diffuse atherosclerotic disease, chronic renal failure or acute coronary syndromes. ${ }^{59}$ Moreover, there may be suboptimal platelet inhibition in such high-risk patients due to pharmacodynamic interaction with other drugs. Multiple studies, as described below and listed in Table 2, support the argument that adequate platelet inhibition is required for thienopyridines for reducing cardiovascular events. There are several methods used to report high platelet reactivity in the clinical trials. These tests use different indices to report platelet reactivity, which include light transmittance aggregometry (LTA), VerifyNow, vasodilator-stimulated phosphoprotein (VASP), Plateletworks, Innovance PFA P2Y IMPACT R assay, and PFA-100 (as shown in Table 1).

\section{Outcome studies}

There are multiple small-size studies and one major outcome study (Table 2) based on PFAs. These studies examined 
Table I Platelet function assay (PFA)

\begin{tabular}{lll}
\hline Method of PFA & High platelet reactivity & Comments \\
\hline LTA (5 micro mol/L ADP) & $>42.9 \%$ aggregation & $\begin{array}{l}\text { Requires dedicated lab with trained technicians; } \\
\text { labor and time intensive }\end{array}$ \\
LTA (20 micro mol/L ADP) & $>64.5 \%$ aggregation & $\begin{array}{l}\text { Requires dedicated lab with trained technicians; } \\
\text { labor and time intensive }\end{array}$ \\
VerifyNow & $>236$ PRU & Fully automated and POC and turnaround time \\
P2YI2 assay & & for test is I5 minutes. VerifyNow P2YI2 Assay \\
& $>50$ PRI & (Accumetrics, San Diego, California) \\
VASP-P & $>80.5 \%$ aggregation & Requires a dedicated lab. Measures platelet \\
& & reactivity index. Requires a flow cytometer \\
Plateletworks assay & Semi-automated POC, time dependent; \\
& Closure time $<1$ I 16 seconds & Helena Laboratories, Beaumont, Texas \\
PFA I00 & $>8.4 \%$ surface coverage & PoC; Siemens Healthcare Diagnostic GMBH, \\
(Collagen/ADP cartridge) & $>3.0 \%$ surface coverage & Extensive sample handing; Matis Medical Inc, \\
IMPACT-R Assay & $>299$ seconds & Beersel, Belgium \\
With and without ADP & & POC; Siemens Healthcare Diagnostic GMBH, \\
Innovance PFA P2Y & Marburg Germany \\
\hline
\end{tabular}

Abbreviations: ADP, adenosine diphosphate; LTA, light transmittance aggregometry; POC, point of care; PRI, platelet reactivity index; PRU, P2YI2 reaction unit; VASP-P, vasodilator-stimulated phosphoprotein phosphorylation.

if suboptimal platelet inhibition translated into major cardiovascular events, using different methodologies. Gurbel et al investigated high platelet reactivity by LTA to ADP and clot strength, a measure of thrombin-induced fibrin, and platelet interaction by thrombelastography. ${ }^{60}$ This study included 192 patients undergoing PCI and postclopidogrel treatment and found that high platelet reactivity by LTA $(63 \% \pm 12 \%$ versus $56 \% \pm 15 \%)$ was associated with higher ischemic events $(P=0.02)$. Similarly, Bliden et al reported high platelet reactivity by LTA in elective PCI patients treated

Table 2 Outcome studies with different inhibition of platelet aggregation

\begin{tabular}{|c|c|c|c|c|c|}
\hline Study & Study patients & Clopidogrel dose & $\begin{array}{l}\text { Platelet function } \\
\text { assay }\end{array}$ & $\begin{array}{l}\text { Platelet reactivity } \\
\text { measure }\end{array}$ & $\begin{array}{l}\text { End-point } \\
\text { prediction }\end{array}$ \\
\hline Matetzky et al ${ }^{6}$ & $\begin{array}{l}\text { STEMI-PCI } \\
\text { patients: } 60\end{array}$ & 300 mg post- $\mathrm{PCl}$ & $\begin{array}{l}\text { LTA } \\
\text { (ADP induced } \\
\text { aggregation) }\end{array}$ & $\begin{array}{l}\text { Patients stratified } \\
\text { into } 4 \text { quartiles }\end{array}$ & $\begin{array}{l}\text { MACE at } 6 \text { months } \\
P<0.0 \text { I }\end{array}$ \\
\hline Gurbel et al ${ }^{60}$ & $\begin{array}{l}\text { ELLECTIVE PCI, } \\
\text { patients: } 192\end{array}$ & $300 / 600$ mg post $\mathrm{PCl}$ & LTA and TEG & $\begin{array}{l}\text { Patients stratified } \\
\text { in different quartiles }\end{array}$ & $\begin{array}{l}\text { MACE at } 6 \text { months } \\
P=0.02\end{array}$ \\
\hline Bliden et $\mathrm{a}^{|6|}$ & $\begin{array}{l}\text { ELLECTIVE PCI, } \\
\text { patients: } 100\end{array}$ & $75 \mathrm{mg}$ for $>$ I month & LTA and TEG & $\begin{array}{l}\text { Pre-procedural platelet } \\
\text { aggregation in patients } \\
\text { on clopidogrel }\end{array}$ & $\begin{array}{l}\text { MACE at } 12 \text { months } \\
P<0.00 \text { I }\end{array}$ \\
\hline Bonello et a $\left.\right|^{38}$ & $\begin{array}{l}\text { ELLECTIVE PCI, } \\
\text { patients: I44 }\end{array}$ & $\begin{array}{l}300 \mathrm{mg}, 24 \text { hours } \\
\text { prior to PCl }\end{array}$ & VASP-P & $\mathrm{PRI}>50 \%$ & $\begin{array}{l}\text { MACE at } 6 \text { months } \\
P<0.0 \text { I }\end{array}$ \\
\hline Price et $\mathrm{al}^{63}$ & $\begin{array}{l}\text { ELLECTIVE PCI, } \\
\text { patients: } 380\end{array}$ & $\begin{array}{l}600 \mathrm{mg}, 12 \text { hours } \\
\text { prior to } \mathrm{PCl}\end{array}$ & VerifyNow & $\mathrm{PRU}>235$ & $\begin{array}{l}\text { MACE at } 6 \text { months } \\
P=0.008\end{array}$ \\
\hline Marcucci et al ${ }^{64}$ & $\begin{array}{l}\text { ACS- PCI } \\
\text { patients: } 683\end{array}$ & $600 \mathrm{mg}$ prior to $\mathrm{PCl}$ & VerifyNow & $\mathrm{PRU}>240$ & $\begin{array}{l}\text { MACE at } 12 \text { months } \\
C V \text { death } P=0.034 \\
M I P=0.004\end{array}$ \\
\hline Migliorini et al ${ }^{62}$ & $\begin{array}{l}\mathrm{PCl} \text { unprotected } \\
\text { LM, patients: } 215\end{array}$ & $600 \mathrm{mg}$ prior to $\mathrm{PCl}$ & LTA & Platelet reactivity > 70\% & $\begin{array}{l}\text { MACE at } 19.3 \text { months } \\
P=0.005\end{array}$ \\
\hline $\begin{array}{l}\text { El Ghannudi } \\
\text { et al }{ }^{65}\end{array}$ & $\begin{array}{l}\text { ELECTIVE and } \\
\text { URGENT PCI, } \\
\text { patients: } 46 \text { I }\end{array}$ & 300 or $600 \mathrm{mg}$ & VASP-P & $\mathrm{PRI}>61 \%$ & $\begin{array}{l}\text { MACE at } 9 \text { months } \\
P=0.037\end{array}$ \\
\hline Breet et al ${ }^{66}$ & $\begin{array}{l}\text { ELLECTIVE PCI, } \\
\text { patients: } 1069\end{array}$ & $\begin{array}{l}75 \mathrm{mg}>5 \text { days or } \\
300 \mathrm{mg}>24 \text { hours prior } \\
\text { or } 600 \mathrm{mg}>4 \text { hours } \\
\text { prior to } \mathrm{PCl}\end{array}$ & $\begin{array}{l}\text { LTA, VerifyNow, } \\
\text { plateletworks, } \\
\text { IMPACT, Innovance } \\
\text { PFA and PFA-100 }\end{array}$ & $\begin{array}{l}\text { Standard Platelet function } \\
\text { measurement values }\end{array}$ & $\begin{array}{l}\text { MACE at } 12 \text { months } \\
P \text { values for tests } \\
\text { shown in Figure } 2\end{array}$ \\
\hline
\end{tabular}

Abbreviations: ADP, adenosine diphosphate; LM, left main; LTA, light transmittance aggregometry; CV, cardiovascular; MACE, major adverse cardiovascular events; MI, myocardial infarction; PFA, platelet function assay; PRI, platelet reactivity index; PRU, P2YI2 reaction unit; TEG, thrombelastography; VASP-P, vasodilator-stimulated phosphoprotein phosphorylation. 
with aspirin and clopidogrel, $23 \%$ of patients with high platelet reactivity had ischemic events $(P<0.001) .{ }^{61}$ In the other outcome study, by Migliorini, high residual platelet reactivity by LTA was evaluated in 215 consecutive patients undergoing placement of a drug-eluting stent with loading of $600 \mathrm{mg}$ of clopidogrel. ${ }^{62}$ In that study, the primary end point was cardiac mortality and secondary end point was stent thrombosis. There was a high residual platelet reactivity in $18.6 \%$ of patients. This high residual platelet reactivity after $600 \mathrm{mg}$ clopidogrel bolus was a strong marker of major cardiovascular events $(P=0.005)$.

Price et al evaluated platelet reactivity with VerifyNow assay in 380 patients undergoing elective PCI. In these patients, the high platelet reactivity was reported as P2Y12 reaction units (PRU). ${ }^{63} \mathrm{PRU} \geq 235$ had a significantly higher rate of cardiovascular death $(2.8 \%$ versus $0 \%, P=0.008)$ and a higher rate of stent thrombosis $(4.6 \%$ versus $0 \%, P=0.004)$ at 6 months. However, another outcome study using VerifyNow for platelet function testing involved 643 patients with acute coronary syndrome undergoing PCI ${ }^{64}$ In this study, all patients received $600 \mathrm{mg}$ loading of clopidogrel and major adverse cardiovascular events at 12 months (cardiovascular death; $P=0.034$, nonfatal myocardial infarction; $P=0.004$ ) was higher in patients with higher residual platelet reactivity; PRU $>240$.

Bonello et al investigated this issue of high platelet reactivity by platelet reactivity index using VASP phosphorylation analysis. ${ }^{38}$ In this study, platelet reactivity predicted postprocedural major adverse cardiovascular events $(P<0.01)$ in 146 patients undergoing PCI with stents and showed a $100 \%$ negative predictive value. Similarly, the VASP test has demonstrated its predictive value for postprocedural PCI with clopidogrel in a study of 346 patients undergoing PCI with a drug-eluting stent after loading with clopidogrel using $300 \mathrm{mg}$ and $600 \mathrm{mg} .{ }^{65}$

The POPULAR (Do Platelet Function Assays Predict Clinical Outcome in Clopidogrel-Pretreated Patients Undergoing Elective PCI) study evaluated the role of higher platelet reactivity by multiple platelet function testing to predict clinical outcome. ${ }^{66}$ This was a prospective, observational single-center study of 1069 patients undergoing coronary stenting with clopidogrel. In this study, platelet reactivity was measured in parallel by multiple PFAs, including LTA, VerifyNow, VASP, Plateletworks, Innovance PFA P2Y IMPACT-R assay, and PFA-100, to predict primary end point of all-cause mortality, nonfatal acute myocardial infarction, stent thrombosis and ischemic stroke. This study found that PFAs, LTA, VerifyNow, Plateletworks, and Innovance PFA
P2Y predicted the primary end point significantly, as illustrated in Figure 1. VASP phosphorylation analysis was not used in this comparative study. ${ }^{38}$

\section{Discussion}

A dual antiplatelet regimen including aspirin with clopidogrel, prasugrel, or ticagrelor reduces atherothrombotic complications in patients undergoing PCI with coronary stents. ${ }^{54,67,68}$ Much attention has been paid to clopidogrel hyporesponsiveness after multiple FDA warnings, without consideration of aspirin hyporesponsiveness, which is a well-known phenomenon. ${ }^{52,69}$ However, individual response to dual antiplatelet regimens with clopidogrel is variable and multiple studies support the hypothesis that variable pharmacodynamic effect may be responsible for atherothrombotic events. ${ }^{6,60,63,64}$ Moreover, hyporesponsiveness to clopidogrel has been found to be an independent predictor of cardiovascular events in patients with ACS undergoing percutaneous interventions, especially in patients with CYP2C19 genetic polymorphism. ${ }^{22}$ A major drawback of these studies has been small sample sizes with evaluation of platelet function by a single assay, as described in Table 2. The popular "Do Platelet Function Assays Predict Clinical Outcome in Clopidogrel-Pretreated Patients Undergoing Elective PCI" trial evaluated the ability of multiple PFAs in the prediction of atherothrombotic events. ${ }^{66}$ This study showed that several PFAs, including LTA, VerifyNow, Plateletworks, and Innovance PFA, predicted cardiovascular events, as shown in Figure 1. Several points of care systems have become available to assess inhibition of aggregation (Table 1). One of the commonly used tests in several previous studies and ongoing studies is VerifyNow. This point-of-care PFA correlated well with LTA, which is considered the gold standard. ${ }^{70}$ It is also relatively inexpensive and easy to perform with excellent reproducibility. Several studies (Table 2) have shown higher ischemic event rates with suboptimal platelet inhibition with VerifyNow reported as PRU $>230$ or high platelet reactivity measured by LTA.

Thienopyridines or nonthienopyridines, such as ticagrelor, inhibit platelet activation via the P2Y12 ADP receptor and the extent of this inhibition is reported as PRU units by VerifyNow. The VerifyNow assay uses ADP and PGE1 to determine platelet reactivity mediated through ADP receptors and a separate channel using thrombin receptors to estimate uninhibited response. This test takes advantage of different receptors of platelet stimulated by different agonists. Thrombin receptors are strong platelet activators and function independent of P2Y12 ADP receptors. Therefore, 

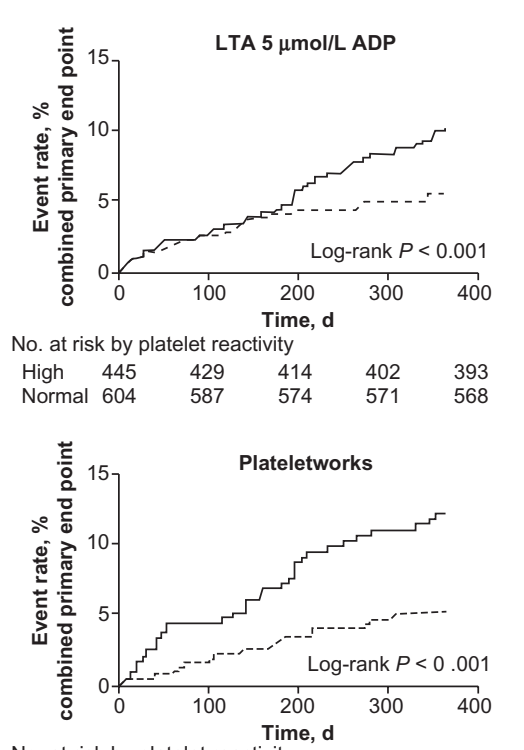

No. at risk by platelet reactivity
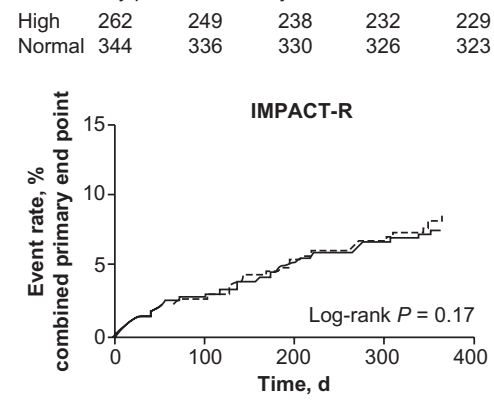

No. at risk by platelet reactivity

$\begin{array}{llllll}\text { High } & 429 & 415 & 402 & 396 & 387 \\ \text { Normal } & 481 & 467 & 455 & 448 & 445\end{array}$

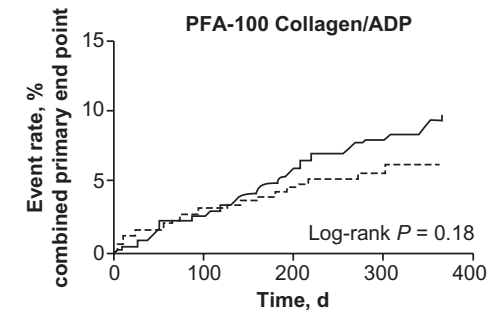

No. at risk by platelet reactivity

$\begin{array}{llllll}\text { High } & 506 & 492 & 473 & 465 & 457 \\ \text { Normal } & 306 & 295 & 290 & 285 & 285\end{array}$
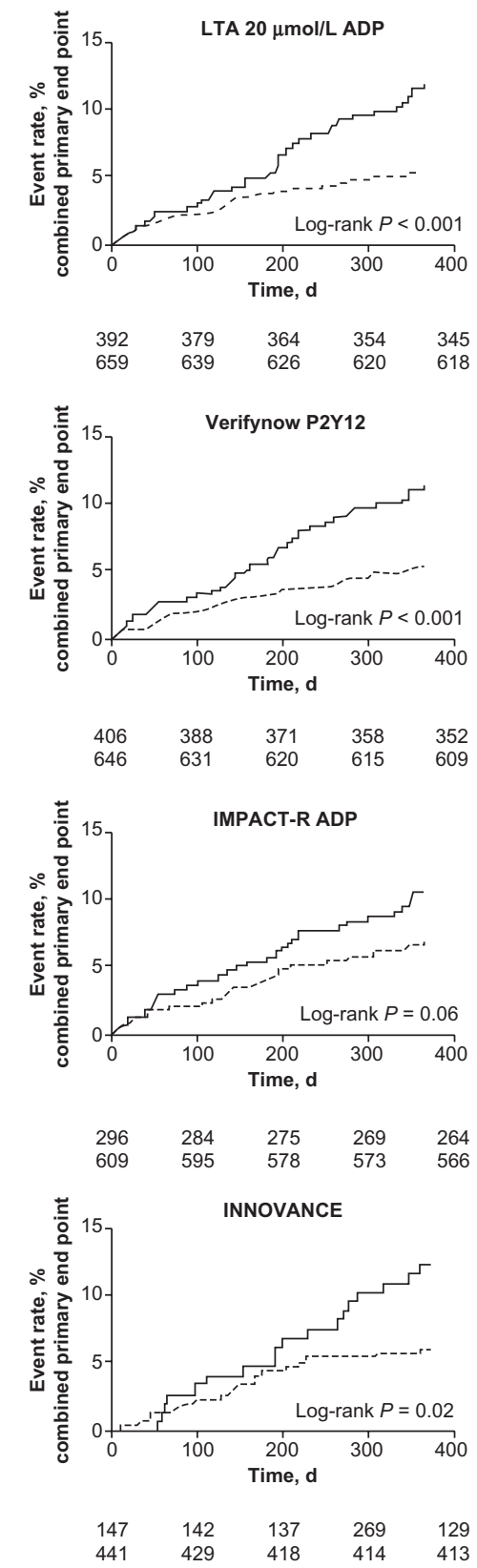

Figure I Kaplan-Meier analysis.

Notes: Kaplan-Meier analysis is for the event rate of the combined primary end point in patients with and without high on-treatment platelet reactivity as measured by multiple platelet function test. Adapted with permission from Breet NJ, van Werkum JW, Bouman HJ, et al. Comparison of platelet function tests in predicting clinical outcome in patients undergoing coronary stent implantation. JAMA. 2010;303(8):754-762. Copyright () 20I0 American Medical Association. All rights reserved.

Abbreviations: ADP, adenosine diphosphate; LTA, light transmittance aggregometry.

the base value (base PRU) is calculated by stimulating these receptors to estimate the total possible platelet aggregation, as if the patient had never received clopidogrel even in the presence of clopidogrel. Then, the extent of platelet inhibition by clopidogrel can be measured by using selective ADP agonist to measure P2Y12 ADP receptor inhibition by thienopyridines or nonthienopyridines. The percent inhibition of P2Y12 ADP receptors is determined by the difference between base PRU and PRU determined from ADP agonist. ${ }^{52}$ However, one needs to understand that the values of the absolute PRU is calculated by ADP agonist; base PRU by thrombin agonist; and percent inhibition on the difference 
of both. It is better to follow the absolute PRU rather than the per cent P2Y12 inhibition, as the calculated per cent P2Y12 inhibition is derived from value obtained from using two different agonists, making a valid comparison difficult.

The PFA to guide and tailor antiplatelet therapy has received considerable attention. One of the major limitations in this field is the lack of definitions for hyporesponder and nonresponder. Tailored antiplatelet therapy is meant to achieve adequate platelet inhibition guided by PFAs. This is an important issue for the possibility of using more potent antiplatelet drugs, like prasugrel and ticagrelor, in patients who are hyporesponders or nonresponders to clopidogrel. Moreover, PFAs may be useful to monitor triple antiplatelet therapy with adjunctive use of cilostazol $^{71}$ or adjunctive use of omega-3 fatty acids. ${ }^{72}$

\section{Algorithm to address issue of hyporesponders or nonresponders to clopidogrel}

Physicians must be aware that genetic factors and nongenetic factors alter clopidogrel metabolism leading to variable inhibition of platelet aggregation. This has been shown to translate into adverse outcomes in clinical trials as discussed above. At the present time, the evidence base is insufficient to recommend routine platelet function testing or routine genetic testing. However clinical judgment is required to assess higher clinical and angiographic risk factors where being a hyporesponder to clopidogrel may lead to a poor outcome and tailored antiplatelet therapy or alternative antiplatelet agent such as prasugrel or ticagrelor may be considered. While there is no expert consensus on routine platelet function testing or genetic testing, certain guidelines have been proposed in high-risk patients with clinical conditions such as diabetes mellitus, diffuse three vessels coronary artery disease, left main stenosis, diffuse atherosclerotic disease or chronic renal failure. ${ }^{59}$ In these patients, an expert panel recommends that platelet function testing or genetic testing may be considered to identify and adequately treat clopidogrel hyporesponders. ${ }^{73,74}$

Due to concern over mortality and morbidity which may be attributable to the suboptimal response to antiplatelet therapy, there are several alternative approaches to standard guidelines. New antiplatelet agents such as prasugrel and

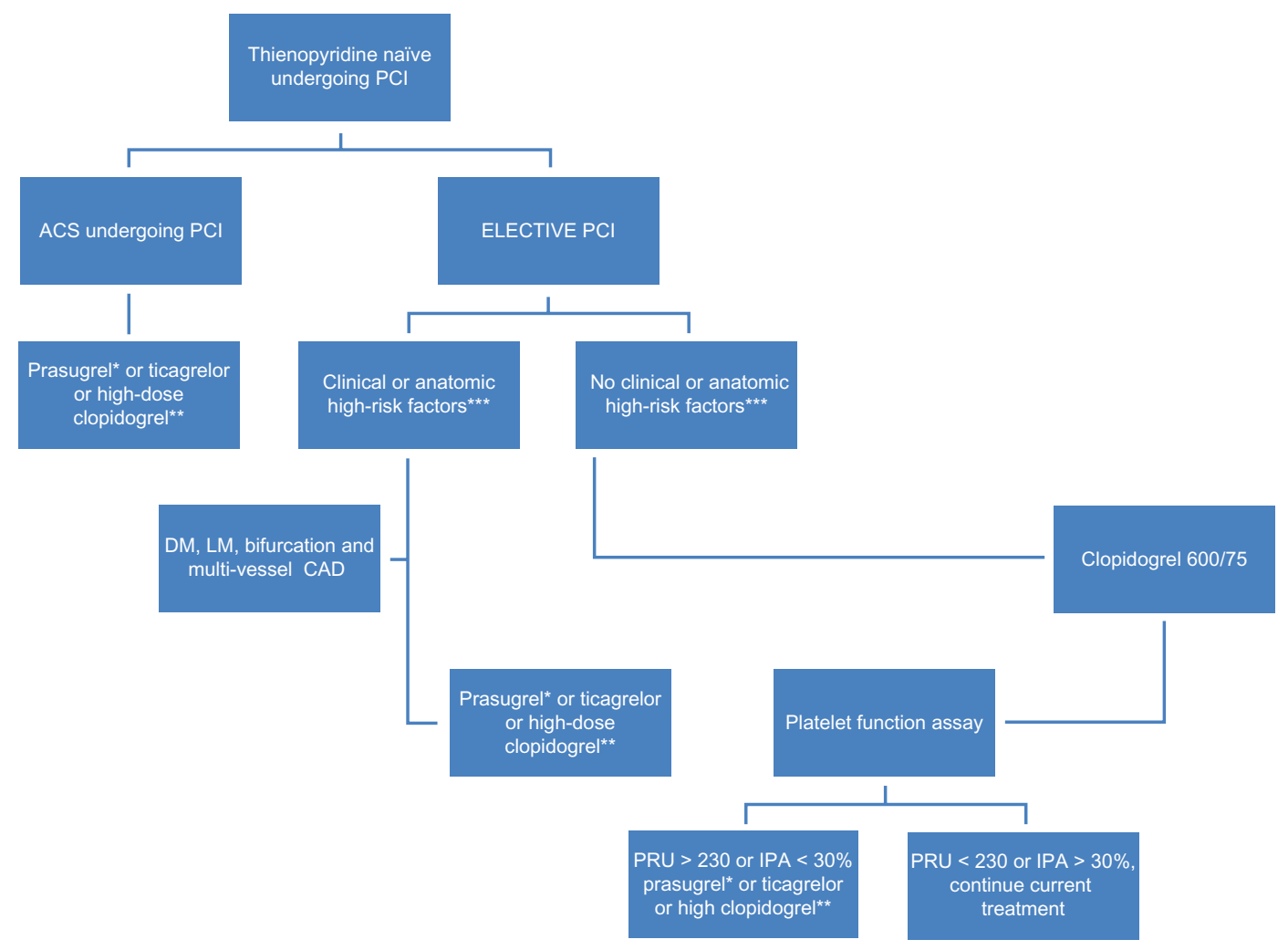

Figure 2 Algorithm based on pharmacodynamic concepts.

Notes: *Contraindicated in patient with history of stroke and TIA. **High-dose clopidogrel option; $600 \mathrm{mg}$ loading and I50 mg daily, guided by platelet function assay. ***Diabetes mellitus, left main stenosis, diffuse atherosclerotic disease, chronic renal failure, and acute coronary syndromes.

Abbreviations: TIA, transient ischemic attack; ACS, acute coronary syndromes; PCI, percutaneous coronary intervention; DM, diabetes mellitus; LM, left main; CAD, coronary artery disease. 
ticagrelor have demonstrated superiority in patients with acute coronary syndrome. ${ }^{54,68}$ These new drugs are not affected by CYP2C19 genetic variants and are more effective, with a more predictable pharmacodynamic response than the standard dose of clopidogrel. While the ongoing trials will expand our understanding of dual antiplatelet regimens and the role of PFA, use of point of care testing to guide treatment in possible hyporesponders or nonresponders to antiplatelet regimen may be useful. At this time, routine clinical use of PFAs to maximize efficacy in PCI cannot be recommended, but for selected patients it may be wise to consider PFAs such as diabetes, multi vessel coronary artery disease, bifurcation stenosis, left main disease or acute coronary syndromes as illustrated in Figure 2 and Figure 3 below. A predictive prognostic algorithm is necessary to individualize antiplatelet therapy with P2Y12 inhibitors based on PFAs and genetic testing. While we wait for definitive trials, the following algorithm may be useful (Figures 2 and 3 ).

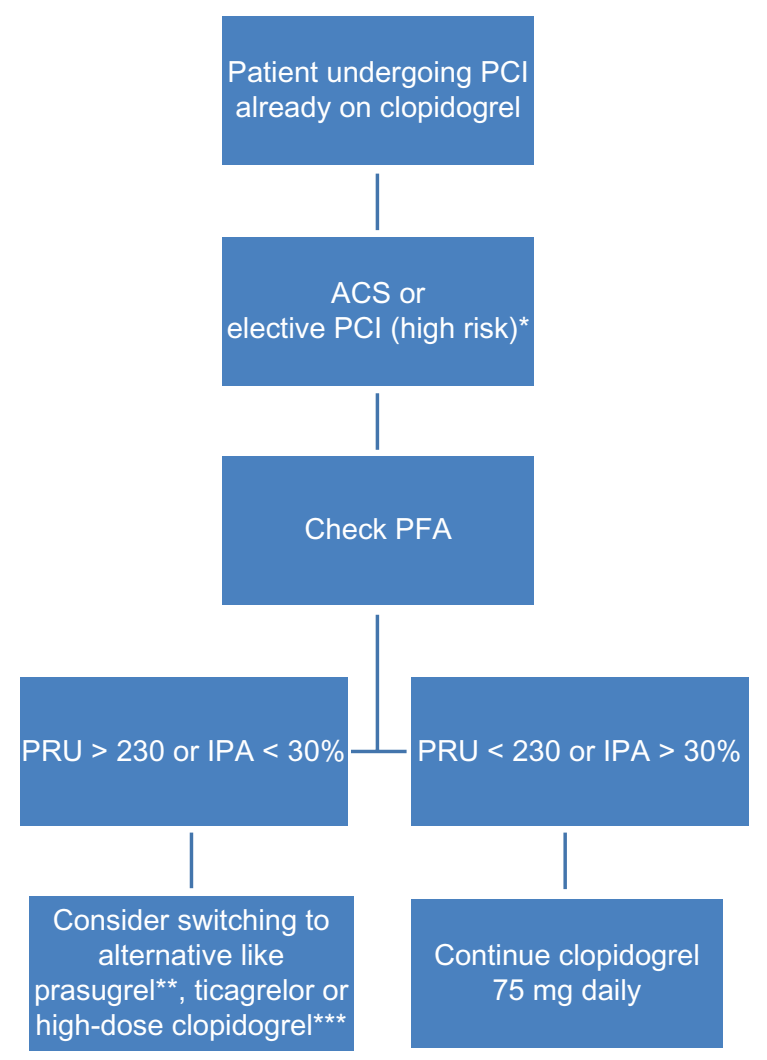

Figure 3 Algorithm based on pharmacodynamic concept.

Notes: *Diabetes mellitus, left main stenosis, diffuse atherosclerotic disease, chronic renal failure and acute coronary syndromes. **Avoid in patients aged $>75$ years or weighing $<60 \mathrm{~kg}$; contraindicated in patients with history of TIA or stroke. ***High-dose clopidogrel option; $600 \mathrm{mg}$ loading and $150 \mathrm{mg}$ daily, guided by PFA.

Abbreviations: IPA, inhibition of platelet aggregation; PFA, platelet function assay; $P R U, P 2 Y I 2$ reaction units; TIA, transient ischemic attack.

\section{Disclosure}

The authors report no conflicts of interest in this work.

\section{References}

1. Wright RS, Anderson JL, Adams CD, et al. 2011 ACCF/AHA focused update of the Guidelines for the Management of Patients with Unstable Angina/Non-ST-Elevation Myocardial Infarction (updating the 2007 guideline): a report of the American College of Cardiology Foundation /American Heart Association Task Force on Practice Guidelines developed in collaboration with the American College of Emergency Physicians, Society for Cardiovascular Angiography and Interventions, and Society of Thoracic Surgeons. J Am Coll Cardiol. 2011;57(19):1920-1959.

2. Anderson JL, Adams CD, Antman EM, et al. ACC/AHA 2007 guidelines for the management of patients with unstable angina/non ST-elevation myocardial infarction: a report of the American College of Cardiology/ American Heart Association Task Force on Practice Guidelines (Writing Committee to Revise the 2002 Guidelines for the Management of Patients With Unstable Angina/Non ST-Elevation Myocardial Infarction): developed in collaboration with the American College of Emergency Physicians, the Society for Cardiovascular Angiography and Interventions, and the Society of Thoracic Surgeons: endorsed by the American Association of Cardiovascular and Pulmonary Rehabilitation and the Society for Academic Emergency Medicine. Circulation. 2007;116(7):e148-e304.

3. Kushner FG, Hand M, Smith SC Jr, et al. 2009 focused updates: ACC/ AHA guidelines for the management of patients with ST-elevation myocardial infarction (updating the 2004 guideline and 2007 focused update) and ACC/AHA/SCAI guidelines on percutaneous coronary intervention (updating the 2005 guideline and 2007 focused update) a report of the American College of Cardiology Foundation/American Heart Association Task Force on Practice Guidelines. J Am Coll Cardiol. 2009;54(23):2205-2241.

4. Iakovou I, Schmidt T, Bonizzoni E, et al. Incidence, predictors, and outcome of thrombosis after successful implantation of drug-eluting stents. JAMA. 2005;293(17):2126-2130.

5. Gurbel PA, Bliden KP, Hiatt BL, O'Connor CM. Clopidogrel for coronary stenting: response variability, drug resistance, and the effect of pretreatment platelet reactivity. Circulation. 2003;107(23):2908-2913.

6. Matetzky S, Shenkman B, Guetta V, et al. Clopidogrel resistance is associated with increased risk of recurrent atherothrombotic events in patients with acute myocardial infarction. Circulation. 2004;109(25):3171-3175.

7. Brandt JT, Payne CD, Wiviott SD, et al. A comparison of prasugrel and clopidogrel loading doses on platelet function: magnitude of platelet inhibition is related to active metabolite formation. Am Heart J. 2007;153(1):66, e69-e16.

8. Taubert D, Kastrati A, Harlfinger S, et al. Pharmacokinetics of clopidogrel after administration of a high loading dose. Thromb Haemost. 2004;92(2):311-316.

9. Jernberg T, Payne CD, Winters KJ, et al. Prasugrel achieves greater inhibition of platelet aggregation and a lower rate of non-responders compared with clopidogrel in aspirin-treated patients with stable coronary artery disease. Eur Heart J. 2006;27(10):1166-1173.

10. Wallentin L, Varenhorst C, James S, et al. Prasugrel achieves greater and faster P2Y12 receptor-mediated platelet inhibition than clopidogrel due to more efficient generation of its active metabolite in aspirin-treated patients with coronary artery disease. Eur Heart J. 2008;29(1):21-30.

11. Erlinge D, Varenhorst C, Braun OO, et al. Patients with poor responsiveness to thienopyridine treatment or with diabetes have lower levels of circulating active metabolite, but their platelets respond normally to active metabolite added ex vivo. J Am Coll Cardiol. 2008;52(24):1968-1977.

12. Gurbel PA, Bliden KP, Hayes KM, Yoho JA, Herzog WR, Tantry US The relation of dosing to clopidogrel responsiveness and the incidence of high post-treatment platelet aggregation in patients undergoing coronary stenting. J Am Coll Cardiol. 2005;45(9):1392-1396. 
13. Picard-Fraire C. Ticlopidine hydrochloride: relationship between dose, kinetics, plasma concentration and effect on platelet function. Thromb Res Suppl. 1983;4:119-128.

14. Wallentin L.P2Y(12) inhibitors: differences in properties and mechanisms of action and potential consequences for clinical use. Eur Heart J. 2009;30(16):1964-1977.

15. Lins R, Broekhuysen J, Necciari J, Deroubaix X. Pharmacokinetic profile of 14C-labeled clopidogrel. Semin Thromb Hemost. 1999;25(Suppl 2):29-33.

16. Caplain H, Donat F, Gaud C, Necciari J. Pharmacokinetics of clopidogrel. Semin Thromb Hemost. 1999;25(Suppl 2):25-28.

17. Ernest CS II, Small DS, Rohatagi S, et al. Population pharmacokinetics and pharmacodynamics of prasugrel and clopidogrel in aspirin-treated patients with stable coronary artery disease. J Pharmacokinet Pharmacodyn. 2008;35(6):593-618.

18. von Beckerath N, Taubert D, Pogatsa-Murray G, Schomig E, Kastrati A, Schomig A. Absorption, metabolization, and antiplatelet effects of 300-, 600-, and 900-mg loading doses of clopidogrel: results of the ISAR-CHOICE (Intracoronary Stenting and Antithrombotic Regimen: Choose Between 3 High Oral Doses for Immediate Clopidogrel Effect) Trial. Circulation. 2005;112(19):2946-2950.

19. Jakubowski JA, Winters KJ, Naganuma H, Wallentin L. Prasugrel: a novel thienopyridine antiplatelet agent. A review of preclinical and clinical studies and the mechanistic basis for its distinct antiplatelet profile. Cardiovasc Drug Rev. 2007;25(4):357-374.

20. Farid NA, Payne CD, Small DS, et al. Cytochrome P450 3 A inhibition by ketoconazole affects prasugrel and clopidogrel pharmacokinetics and pharmacodynamics differently. Clin Pharmacol Ther. 2007;81(5):735-741.

21. Clarke TA, Waskell LA. The metabolism of clopidogrel is catalyzed by human cytochrome P450 3A and is inhibited by atorvastatin. Drug Metab Dispos. 2003;31(1):53-59.

22. Mega JL, Close SL, Wiviott SD, et al. Cytochrome p-450 polymorphisms and response to clopidogrel. N Engl J Med. 2009;360(4):354-362.

23. Brandt JT, Close SL, Iturria SJ, et al. Common polymorphisms of CYP2C19 and CYP2C9 affect the pharmacokinetic and pharmacodynamic response to clopidogrel but not prasugrel. J Thromb Haemost. 2007;5(12):2429-2436.

24. Farid NA, Smith RL, Gillespie TA, et al. The disposition of prasugrel, a novel thienopyridine, in humans. Drug Metab Dispos. 2007;35(7):1096-1104.

25. Williams ET, Jones KO, Ponsler GD, et al. The biotransformation of prasugrel, a new thienopyridine prodrug, by the human carboxylesterases 1 and 2. Drug Metab Dispos. 2008;36(7):1227-1232.

26. Rehmel JL, Eckstein JA, Farid NA, et al. Interactions of two major metabolites of prasugrel, a thienopyridine antiplatelet agent, with the cytochromes P450. Drug Metab Dispos. 2006;34(4):600-607.

27. Storey RF, Husted S, Harrington RA, et al. Inhibition of platelet aggregation by AZD6140, a reversible oral P2Y12 receptor antagonist, compared with clopidogrel in patients with acute coronary syndromes. J Am Coll Cardiol. 2007;50(19):1852-1856.

28. Husted S, Emanuelsson H, Heptinstall S, Sandset PM, Wickens M, Peters G. Pharmacodynamics, pharmacokinetics, and safety of the oral reversible P2Y12 antagonist AZD6140 with aspirin in patients with atherosclerosis: a double-blind comparison to clopidogrel with aspirin. Eur Heart J. 2006;27(9):1038-1047.

29. Storey RF, Oldroyd KG, Wilcox RG. Open multicentre study of the P2T receptor antagonist AR-C69931MX assessing safety, tolerability and activity in patients with acute coronary syndromes. Thromb Haemost. 2001;85(3):401-407.

30. Gurbel PA, Bliden KP, Antonino MJ, et al. The effect of elinogrel on high platelet reactivity during dual antiplatelet therapy and the relation to CYP2C19*2 genotype: first experience in patients. J Thromb Haemost. 2010;8(1):43-53.

31. Davi G, Patrono C. Platelet activation and atherothrombosis. $N$ Engl J Med. 2007;357(24):2482-2494.

32. Jin J, Daniel JL, Kunapuli SP. Molecular basis for ADP-induced platelet activation. II. The P2Y1 receptor mediates ADP-induced intracellular calcium mobilization and shape change in platelets. J Biol Chem. 1998;273(4):2030-2034.
33. Daniel JL, Dangelmaier C, Jin J, Ashby B, Smith JB, Kunapuli SP. Molecular basis for ADP-induced platelet activation. I. Evidence for three distinct ADP receptors on human platelets. J Biol Chem. 1998;273(4):2024-2029.

34. Daniel JL, Dangelmaier C, Jin J, Kim YB, Kunapuli SP. Role of intracellular signaling events in ADP-induced platelet aggregation. Thromb Haemost. 1999;82(4):1322-1326.

35. Anderson JL, Adams CD, Antman EM, et al. ACC/AHA 2007 guidelines for the management of patients with unstable angina/nonST-Elevation myocardial infarction: a report of the American College of Cardiology/American Heart Association Task Force on Practice Guidelines (Writing Committee to Revise the 2002 Guidelines for the Management of Patients With Unstable Angina/ Non-ST-Elevation Myocardial Infarction) developed in collaboration with the American College of Emergency Physicians, the Society for Cardiovascular Angiography and Interventions, and the Society of Thoracic Surgeons endorsed by the American Association of Cardiovascular and Pulmonary Rehabilitation and the Society for Academic Emergency Medicine. J Am Coll Cardiol. 2007;50(7):e1-e157.

36. Wiviott SD, Trenk D, Frelinger AL, et al. Prasugrel compared with high loading- and maintenance-dose clopidogrel in patients with planned percutaneous coronary intervention: the Prasugrel in Comparison to Clopidogrel for Inhibition of Platelet Activation and AggregationThrombolysis in Myocardial Infarction 44 trial. Circulation. 2007;116(25):2923-2932.

37. Cuisset T, Frere C, Quilici J, et al. High post-treatment platelet reactivity identified low-responders to dual antiplatelet therapy at increased risk of recurrent cardiovascular events after stenting for acute coronary syndrome. J Thromb Haemost. 2006;4(3):542-549.

38. Bonello L, Paganelli F, Arpin-Bornet M, et al. Vasodilator-stimulated phosphoprotein phosphorylation analysis prior to percutaneous coronary intervention for exclusion of postprocedural major adverse cardiovascular events. J Thromb Haemost. 2007;5(8):1630-1636.

39. Buonamici P, Marcucci R, Migliorini A, et al. Impact of platelet reactivity after clopidogrel administration on drug-eluting stent thrombosis. J Am Coll Cardiol. 2007;49(24):2312-2317.

40. Splawinska B, Kuzniar J, Malinga K, Mazurek AP, Splawinski J. The efficacy and potency of antiplatelet activity of ticlopidine is increased by aspirin. Int J Clin Pharmacol Ther. 1996;34(8):352-356.

41. Altman R, Scazziota A, Rouvier J, Gonzalez C. Effects of ticlopidine or ticlopidine plus aspirin on platelet aggregation and ATP release in normal volunteers: why aspirin improves ticlopidine antiplatelet activity. Clin Appl Thromb Hemost. 1999;5(4):243-246.

42. Cuisset T, Frere C, Quilici J, et al. Benefit of a 600-mg loading dose of clopidogrel on platelet reactivity and clinical outcomes in patients with non-ST-segment elevation acute coronary syndrome undergoing coronary stenting. J Am Coll Cardiol. 2006;48(7):1339-1345.

43. Montalescot G, Sideris G, Meuleman C, et al. A randomized comparison of high clopidogrel loading doses in patients with non-ST-segment elevation acute coronary syndromes: the ALBION (Assessment of the Best Loading Dose of Clopidogrel to Blunt Platelet Activation, Inflammation and Ongoing Necrosis) trial. JAm Coll Cardiol. 2006;48(5): 931-938.

44. Angiolillo DJ, Fernandez-Ortiz A, Bernardo E, et al. High clopidogrel loading dose during coronary stenting: effects on drug response and interindividual variability. Eur Heart J. 2004;25(21):1903-1910.

45. Kastrati A, von Beckerath N, Joost A, Pogatsa-Murray G, Gorchakova O, Schomig A. Loading with $600 \mathrm{mg}$ clopidogrel in patients with coronary artery disease with and without chronic clopidogrel therapy. Circulation. 2004;110(14):1916-1919.

46. Michelson AD, Frelinger AL III, Braunwald E, et al. Pharmacodynamic assessment of platelet inhibition by prasugrel vs. clopidogrel in the TRITON-TIMI 38 trial. Eur Heart J. 2009;30(14):1753-1763.

47. Jakubowski JA, Payne CD, Brandt JT, et al. The platelet inhibitory effects and pharmacokinetics of prasugrel after administration of loading and maintenance doses in healthy subjects. J Cardiovasc Pharmacol. 2006;47(3):377-384. 
48. Payne CD, Li YG, Small DS, et al. Increased active metabolite formation explains the greater platelet inhibition with prasugrel compared to highdose clopidogrel. J Cardiovasc Pharmacol. 2007;50(5):555-562.

49. Holmes DR Jr, Dehmer GJ, Kaul S, Leifer D, O’Gara PT, Stein CM. ACCF/AHA Clopidogrel Clinical Alert: Approaches to the FDA "Boxed Warning": A Report of the American College of Cardiology Foundation Task Force on Clinical Expert Consensus Documents and the American Heart Association Endorsed by the Society for Cardiovascular Angiography and Interventions and the Society of Thoracic Surgeons. J Am Coll Cardiol. 2010 2010;56(4):321-341.

50. Bristol-Myers Squibb/Sanofi Pharmaceutical Partnership. Plavix Full Prescribing Information.

51. Muller I, Besta F, Schulz C, Massberg S, Schonig A, Gawaz M. Prevalence of clopidogrel non-responders among patients with stable angina pectoris scheduled for elective coronary stent placement. Thromb Haemost. 2003;89(5):783-787.

52. Sharma RK, Reddy HK, Singh VN, Sharma R, Voelker DJ, Bhatt G. Aspirin and clopidogrel hyporesponsiveness and nonresponsiveness in patients with coronary artery stenting. Vasc Health Risk Manag. 2009;5:965-972.

53. Bhatt DL, Scheiman J, Abraham NS, et al. ACCF/ACG/AHA 2008 expert consensus document on reducing the gastrointestinal risks of antiplatelet therapy and NSAID use: a report of the American College of Cardiology Foundation Task Force on Clinical Expert Consensus Documents. Circulation. 2008;118(18):1894-1909.

54. Wiviott SD, Braunwald E, McCabe CH, et al. Prasugrel versus clopidogrel in patients with acute coronary syndromes. $N$ Engl $J$ Med. 2007;357(20):2001-2015.

55. O'Donoghue ML, Braunwald E, Antman EM, et al. Pharmacodynamic effect and clinical efficacy of clopidogrel and prasugrel with or without a proton-pump inhibitor: an analysis of two randomised trials. Lancet. 2009;374(9694):989-997.

56. Sharma RK, Reddy HK, Sharma R, et al. The Interaction between clopidogrel and proton pump inhibtors (PPI): is there any clinical relevance. Clinical Pharmacology: Advances and Applications. 2011;2:155-162.

57. Shuldiner AR, O'Connell JR, Bliden KP, et al. Association of cytochrome $\mathrm{P} 4502 \mathrm{C} 19$ genotype with the antiplatelet effect and clinical efficacy of clopidogrel therapy. JAMA. 2009;302(8):849-857.

58. Simon T, Verstuyft C, Mary-Krause M, et al. Genetic determinants of response to clopidogrel and cardiovascular events. $N$ Engl J Med. 2009;360(4):363-375.

59. Holmes DR Jr, Dehmer GJ, Kaul S, Leifer D, O'Gara PT, Stein CM. ACCF/ AHA Clopidogrel Clinical Alert: Approaches to the FDA "Boxed Warning" A Report of the American College of Cardiology Foundation Task Force on Clinical Expert Consensus Documents and the American Heart Association Endorsed by the Society for Cardiovascular Angiography and Interventions and the Society of Thoracic Surgeons. J Am Coll Cardiol. 2010;56(4):321-341.

60. Gurbel PA, Bliden KP, Guyer K, et al. Platelet reactivity in patients and recurrent events post-stenting: results of the PREPARE POSTSTENTING Study. J Am Coll Cardiol. 2005;46(10):1820-1826.

61. Bliden KP, DiChiara J, Tantry US, Bassi AK, Chaganti SK, Gurbel PA. Increased risk in patients with high platelet aggregation receiving chronic clopidogrel therapy undergoing percutaneous coronary intervention: is the current antiplatelet therapy adequate? $\mathrm{J} \mathrm{Am} \mathrm{Coll} \mathrm{Cardiol}$. 2007;49(6):657-666.
62. Migliorini A, Valenti R, Marcucci R, et al. High residual platelet reactivity after clopidogrel loading and long-term clinical outcome after drug-eluting stenting for unprotected left main coronary disease. Circulation. 2009;120(22):2214-2221.

63. Price MJ, Endemann S, Gollapudi RR, et al. Prognostic significance of post-clopidogrel platelet reactivity assessed by a point-of-care assay on thrombotic events after drug-eluting stent implantation. Eur Heart J. 2008;29(8):992-1000.

64. Marcucci R, Gori AM, Paniccia R, et al. Cardiovascular death and nonfatal myocardial infarction in acute coronary syndrome patients receiving coronary stenting are predicted by residual platelet reactivity to ADP detected by a point-of-care assay: a 12-month follow-up. Circulation. 2009;119(2):237-242.

65. El Ghannudi S, Ohlmann P, Meyer N, et al. Impact of P2Y12 inhibition by clopidogrel on cardiovascular mortality in unselected patients treated by percutaneous coronary angioplasty: a prospective registry. JACC. Cardiovascular interventions. 2010;3(6):648-656.

66. Breet NJ, van Werkum JW, Bouman HJ, et al. Comparison of platelet function tests in predicting clinical outcome in patients undergoing coronary stent implantation. JAMA. 2010;303(8):754-762.

67. Steinhubl SR, Berger PB, Mann JT III, et al. Early and sustained dual oral antiplatelet therapy following percutaneous coronary intervention: a randomized controlled trial. JAMA. 2002;288(19):2411-2420.

68. Wallentin L, Becker RC, Budaj A, et al. Ticagrelor versus clopidogrel in patients with acute coronary syndromes. $N$ Engl J Med. 2009;361(11):1045-1057.

69. Lev EI, Patel RT, Maresh KJ, et al. Aspirin and clopidogrel drug response in patients undergoing percutaneous coronary intervention: the role of dual drug resistance. J Am Coll Cardiol. 2006;47(1):27-33.

70. Gurbel PA, Becker RC, Mann KG, Steinhubl SR, Michelson AD. Platelet function monitoring in patients with coronary artery disease. J Am Coll Cardiol. 2007;50(19):1822-1834.

71. Ha S. Effect of Cilostazol adding or clopidogrel doubling on platelet function with diabetes and coronary artery disease on dual antiplatelet therapy. J Am Coll Cardiol. 2010;55(A113.E 1058).

72. Gajos G, Rostoff P, Undas A, Piwowarska W. Effects of polyunsaturated omega-3 fatty acids on responsiveness to dual antiplatelet therapy in patients undergoing percutaneous coronary intervention: the OMEGA-PCI (OMEGA-3 fatty acids after pci to modify responsiveness to dual antiplatelet therapy) study. J Am Coll Cardiol. 2010;55(16):1671-1678.

73. Wright RS, Anderson JL, Adams CD, et al. 2011 ACCF/AHA focused update incorporated into the ACC/AHA 2007 Guidelines for the Management of Patients with Unstable Angina/Non-ST-Elevation Myocardial Infarction: a report of the American College of Cardiology Foundation/American Heart Association Task Force on Practice Guidelines developed in collaboration with the American Academy of Family Physicians, Society for Cardiovascular Angiography and Interventions, and the Society of Thoracic Surgeons. J Am Coll Cardiol. 2011;57(19):e215-367.

74. Holmes DR Jr, Dehmer GJ, Kaul S, Leifer D, O'Gara PT, Stein CM. ACCF/AHA Clopidogrel Clinical Alert: Approaches to the FDA "Boxed Warning". A Report of the American College of Cardiology Foundation Task Force on Clinical Expert Consensus Documents and the American Heart Association. J Am Coll Cardiol. 2010;56(4):321-341.
Vascular Health and Risk Management

\section{Publish your work in this journal}

Vascular Health and Risk Management is an international, peerreviewed journal of therapeutics and risk management, focusing on concise rapid reporting of clinical studies on the processes involved in the maintenance of vascular health; the monitoring, prevention and treatment of vascular disease and its sequelae; and the involvement of

\section{Dovepress}

metabolic disorders, particularly diabetes. This journal is indexed on PubMed Central and MedLine. The manuscript management system is completely online and includes a very quick and fair peer-review system, which is all easy to use. Visit http://www.dovepress.com/ testimonials.php to read real quotes from published authors. 